\title{
A DESJUDICIALIZAÇÃO DAS DEMANDAS POR MEDICAMENTOS: UMA ANÁLISE SOBRE A EFETIVIDADE DO NÚCLEO DE APOIO TÉCNICO - NAT APÓS A SUA INSTALAÇÃO NO MUNICÍPIO DE JOINVILLE
}

\section{THE DISMISSAL OF DRUG DEMANDS: AN ANALYSIS OF THE EFFECTIVENESS OF THE TECHNICAL SUPPORT NUCLEUS - NAT AFTER ITS INSTALLATION IN THE MUNICIPALITY OF JOINVILLE}

\section{Thaíse Siqueira Ornelas ${ }^{1}$}

RESUMO: O presente estudo visa avaliar se o Núcleo de Apoio Técnico - NAT do Município de Joinville é dotado de efetividade, a qual, entende-se, é a capacidade de produzir um resultado para transformar a situação existente, respondendo adequadamente às necessidades da comunidade. Para tanto, faz-se um breve resgate histórico da judicialização da saúde no Brasil, com a análise da evolução da jurisprudência sobre o tema e das medidas adotadas pelo Poder Público para conter o crescimento exponencial do número de processos judiciais e dos gastos públicos correspondentes. No Estado de Santa Catarina, destaca-se o julgamento do Incidente de Resolução de Demandas Repetitivas (Tema 1), a instalação do Comitê Estadual de Monitoramento e Resolução das Demandas de Assistência da Saúde de Santa Catarina - COMESC e a criação do Núcleo de Apoio Técnico - NAT, com a finalidade de assessorar o Poder Judiciário, com informações técnicas e esclarecedoras sobre o atendimento no SUS, bem como de otimizar o atendimento do usuário, mediante a indicação do tratamento preconizado no SUS, quando existir, e, na sua ausência, da alternativa terapêutica existente. Em arremate, há uma análise dos indicadores apresentados no Relatório

1 Bacharel em direito pela Universidade Federal de Santa Catarina; pós-Graduação Lato Sensu em Direito, Estado e Constituição pela Faculdades Integradas da União Educacional do Planalto Central. Juíza Substituta da $15^{\text {a }}$ Circunscrição, lotada na Comarca de Joinville.Email:thaiseornelas@gmail.com. 
Anual de Monitoramento da Judicialização - 2017 da Secretaria Municipal de Saúde de Joinville e dos serviços prestados à população local pelo NAT instalado naquela cidade.

Palavras-chave: Judicialização. Saúde. Apoio. NAT. Joinville.

ABSTRACT: The present study aims to evaluate if the Technical Support Center - NAT of the Municipality of Joinville is endowed with effectiveness, which, it is understood, is the capacity to produce a result to transform the existing situation, responding adequately to the needs of the community. To do so, a brief historical rescue of the judicialization of health in Brazil is made, analyzing the evolution of jurisprudence on the subject and the measures adopted by the Government to contain the exponential growth in the number of lawsuits and corresponding public expenditures. In the state of Santa Catarina, the trial of the Incident of Repetitive Claims Resolution (Theme 1), the installation of the State Committee for Monitoring and Resolution of Health Care Claims of Santa Catarina (COMESC) and the creation of the Technical Support Nucleus NAT, with the purpose of advising the Judiciary Power, with technical and enlightening information about the SUS care, as well as optimizing the user's care, indicating the treatment recommended in the SUS, when it exists, and, in its absence, of the existing therapeutic alternative. In closing, there is an analysis of the indicators presented in the Annual Monitoring Report of the Judicialization - 2017 of the Municipal Health Department of Joinville and the services rendered to the local population by the NAT installed in that city.

Keywords: Judicialization. Health. Support. NAT. Joinville.

\section{INTRODUÇÃ̃O}

O direito à saúde, como corolário da dignidade da pessoa humana, está previsto no Título II da Constituição Federal, que trata dos direitos e garantias fundamentais (artigo $6^{\circ}$, caput).

A dignidade da pessoa humana, fundamento da República Federativa do Brasil (CRFB, art. $1^{\circ}$, III), é reconhecida não só como princípio fundamental, mas também vetor de todo o sistema jurídico brasileiro.

Para Barroso (2014, p. 64):

A dignidade humana, portanto, é um valor fundamental, mas não deve ser tomada como absoluta. Valores, sejam políticos ou morais, adentram o mundo do direito usualmente assumindo a forma de princípios. E embora direitos 
constitucionais e princípios constitucionais frequentemente se justaponham, esse não é exatamente o caso aqui. A melhor maneira de classificar a dignidade humana é como um princípio jurídico com status constitucional, e não como um direito autônomo. [...] Como um valor fundamental que é também um princípio constitucional, a dignidade humana funciona tanto como justificação moral quanto como fundamento jurídico-normativo dos direitos fundamentais.

Seguindo a lição de Alexy (2011, p.88), princípios são mandados de otimização e, por isso, devem ser aplicados mediante ponderação do intérprete, gradualmente, conforme a possibilidade jurídica e social de sua efetiva concretização.

Desta forma, a dignidade da pessoa humana não pode ser compreendida como um princípio absoluto, mas como uma garantia de pleno gozo dos direitos tipicamente fundamentais pelos indivíduos.

Ao conceituar direitos fundamentais, Silva (2017, p. 180) explica que:

Direitos fundamentais do homem constitui a expressão mais adequada a este estudo, porque, além de referir-se a princípios que resumem a concepção do mundo e informam a ideologia política de cada ordenamento jurídico, é reservada para designar, no nível do direito positivo, aquelas prerrogativas e instituições que ele concretiza em garantias de uma convivência digna, livre e igual de todas as pessoas. No qualificativo fundamental acha-se a indicação de que se trata de situações jurídicas sem as quais a pessoa humana não se realiza, não convive e, às vezes, nem mesmo sobrevive; fundamentais do homem no sentido de que a todos, por igual, devem ser, não apenas formalmente reconhecidos, mas concreta e materialmente efetivados. Do homem, não como o macho da espécie, mas no sentido de pessoa humana. Direitos fundamentais do homem significa direitos fundamentais da pessoa humana ou direitos fundamentais.

Na Constituição Federal, o direito fundamental à saúde está estampado no artigo 196, nos seguintes termos: 
A saúde é direito de todos e dever do Estado, garantido mediante políticas sociais e econômicas que visem à redução do risco de doença e de outros agravos e ao acesso universal e igualitário às ações e serviços para sua promoção, proteção e recuperação (BRASIL, 1988).

No que se refere ao direito fundamental à saúde, Silva (2017, p. 311-312) explica que:

Há de informar-se pelo princípio de que o direito igual a vida de todos os seres humanos significa também que, nos casos de doença, cada um tem o direito a um tratamento condigno de acordo com o estado atual da ciência médica, independentemente de sua situação econômica, sob pena de não ter muito valor sua consignação em normas constitucionais. [...] Como ocorre com os direitos sociais em geral, o direito à saúde comporta duas vertentes, conforme anotam Gomes Canotilho e Vital Moreira: 'uma de natureza negativa, que consiste no direito a exigir do Estado (ou de terceiros) que se abstenha de qualquer acto que prejudique a saúde; outra, de natureza positiva, que significa o direito às medidas e prestações estaduais visando a prevenção das doenças e o tratamento delas'. Como se viu do enunciado do art. 196 e se confirmará com a leitura dos arts. 198 a 200 , trata-se de um direito positivo 'que exige prestações de Estado e que impõe aos entes públicos a realização de determinadas tarefas [...], de cujo cumprimento depende a própria realização do direito'.

A Carta Magna estabelece, ainda, no seu art. 194, parágrafo único, I, que o atendimento integral é diretriz constitucional, sendo solidário o dever da União, Estados e Municípios, no sentido de garantir a "universalidade da cobertura e do atendimento." (BRASIL, 1988).

Assim, por ser a saúde matéria de competência solidária da União, Estados e Municípios e, portanto, obrigação comum a todos eles, pode a pessoa acometida de doença exigir os procedimentos necessários ao tratamento de sua saúde de qualquer um desses entes federativos. 
Ocorre que muitas vezes esse direito é violado e quando isso acontece muitos recorrem ao Poder Judiciário para ter acesso a medicamentos, tratamentos médicos ou mesmo uma vaga em hospital.

Em valiosa obra sobre o tema da judicialização da saúde no Brasil, Schulze e Gebran Neto, (2015, p. 29) explicam que:

A principal causa de insatisfação social decorre da incapacidade do Estado de concretizar plenamente o direito à saúde. O Brasil é um país de extremos também no que se refere ao presente tema. De um lado, o SUS demonstra a capacidade de patrocinar e manter os melhores tratamentos do mundo aos portadores de HIV ou de promover transplantes de alta complexidade. De outro lado, é incapaz de prestar atenção básica de saúde a grande parte da população, principalmente quando distante das grandes capitais.

Ainda, afirmam que essa atuação deficiente dos Poderes Executivo e Legislativo na área da saúde é uma das causas da ascensão do Poder Judiciário, pois, se o serviço público de saúde não funciona ou funciona de modo insatisfatório, invariavelmente o cidadão vai buscar a tutela jurisdicional.

Nesse cenário, as decisões judiciais, ao concederem a tutela pretendida em tais demandas, para além de assegurarem o direito fundamental à saúde, provocam impactos no orçamento público e na própria atividade do Poder Judiciário, com o deslocamento de recursos públicos e aumento vertiginoso do número de processos.

Toda essa situação vai de encontro ao disposto no art. 37, caput, da Constituição Federal, segundo o qual "A administração Pública direta e indireta de qualquer dos Poderes da União, dos Estados, do Distrito Federal e dos Municípios obedecerá aos princípios de legalidade, impessoalidade, moralidade, publicidade e eficiência [...]" (grifo nosso)

Sobre o princípio da eficiência, Carvalho Filho (2017, p. 
31) leciona que "A $\mathrm{EC} \mathrm{n}^{\circ}$ 19/1998, que guindou ao plano constitucional as regras relativas ao projeto de reforma do Estado, acrescentou, ao caput do art. 37, outro princípio, o da eficiência (denominado de 'qualidade do serviço prestado' no projeto de Emenda)."

Atento ao comando constitucional de atuar com eficiência, o Poder Público tem investido em alternativas para reduzir o número de demandas judiciais e dar suporte técnico aos juízes para que as suas decisões sejam cada vez mais qualificadas e fundamentadas.

No Estado de Santa Catarina, tanto o Poder Judiciário quanto o Poder Executivo têm atuado positivamente para alcançar maior eficiência no desempenho das suas atribuições, visando à redução do número de ações judiciais e do gasto público com demandas por medicamentos/procedimentos/ materiais relativos à saúde.

O presente estudo, cujo tema é "A desjudicialização das demandas por medicamentos: uma análise sobre a efetividade do Núcleo de Apoio Técnico - NAT após a sua instalação no Município de Joinville", parte da concepção pessoal desta pesquisadora, como magistrada, de que o modelo tradicional de resolução de demandas na área da saúde pela via estritamente judicial é ineficiente.

Desta forma, este artigo visa avaliar se a implantação do NAT no Município de Joinville foi efetiva na redução dos gastos públicos com demandas judiciais por medicamentos e tratamentos médicos, na diminuição do número de entradas de processos judiciais relacionados ao tema na Comarca de Joinville, bem como na melhoria da qualidade do serviço público municipal de saúde prestado.

Para tanto, faz-se, inicialmente, uma análise histórica da judicialização da saúde no Brasil. Em seguida, são apresenta- 
das algumas medidas adotadas pelo Poder Público para conter a enxurrada de processos judiciais e o aumento progressivo de gastos públicos nas demandas por medicamentos/procedimentos/materiais relacionados à saúde, dentre eles o Núcleo de Apoio Técnico - NAT. Por fim, são apresentados os indicadores no Município de Joinville, com a avaliação da efetividade deste órgão quanto às suas finalidades.

Os delineamentos da pesquisa deram-se em função dos objetivos,dos procedimentos e da abordagem do problema, adotando-se o método descritivo. Na apuração dos dados, foi realizada uma pesquisa bibliográfica, com análise de atos normativos, atos administrativos, artigos científicos e livros que abordam o assunto, bem como visita ao local em que funciona a sede do NAT. Além disso, foram coletados dados da Secretaria Municipal de Saúde do Município de Joinville, inclusive, mediante entrevista ao Gerente de Acompanhamento de Processos, Sr. Andrei Popovski Kolaceke.

\section{DESENVOLVIMENTO}

No Brasil, as primeiras ações em que se discutia o direito à saúde chegaram aos tribunais superiores em meados da década de 90 e buscavam basicamente o acesso aos medicamentos já disponibilizados pelo Estado. A partir de então, especialmente a partir do início dos anos 2000, o que se observou foi o aumento exponencial de demandas dessa espécie e a evolução da jurisprudência do Supremo Tribunal Federal - STF e do Superior Tribunal de Justiça - STJ.

Num primeiro momento, o entendimento majoritário destes tribunais era no sentido da impossibilidade de interferência do Poder Judiciário nas políticas públicas de saúde, a exemplo do que se decidiu no Recurso em Mandado de Segurança n. 6564/RS, julgado pelo STJ, em 23 de maio de 1996: 
CONSTITUCIONAL. ADMINISTRATIVO. MANDADO DE SEGURANÇA. DIREITO LIQUIDO E CERTO. INEXISTENCIA. DIREITO LIQUIDO E CERTO, PARA EFEITO DE CONCESSÃO DE SEGURANÇA, E AQUELE RECONHECÍVEL DE PLANO E DECORRENTE DE LEI EXPRESSA OU DE PRECEITO CONSTITUCIONAL, QUE ATRIBUA, AO IMPETRANTE, UM DIREITO SUBJETIVO PRÓPRIO. NORMAS CONSTITUCIONAIS MERAMENTE PROGRAMÁTICAS - AD EXEMPLUM, O DIREITO A SAUDE - PROTEGEM UM INTERESSE GERAL, TODAVIA, NÃO CONFEREM, AOS BENEFICIÁRIOS DESSE INTERESSE, O PODER DE EXIGIR SUA SATISFAÇÃO - PELA VIA DO MANDAMUS - EIS QUE NÃO DELIMITADO O SEU OBJETO, NEM FIXADA A SUA EXTENSÃO, ANTES QUE O LEGISLADOR EXERÇA O MUNUS DE COMPLETÁ-LAS ATRAVES DA LEGISLAÇÃO INTEGRATIVA. ESSAS NORMAS (ARTS. 195, 196, 204 E 227 DA CF) SÃO DE EFICÁCIA LIMITADA, OU, EM OUTRAS PALAVRAS, NÃO TÊM FORÇA SUFICIENTE PARA DESENVOLVER-SE INTEGRALMENTE, 'OU NÃO DISPÕEM DE EFICÁCIA PLENA', POSTO QUE DEPENDEM, PARA TER INCIDÊNCIA SOBRE OS INTERESSES TUTELADOS, DE LEGISLAÇÃO COMPLEMENTAR. NA REGRA JURÍDICO-CONSTITUCIONAL QUE DISPÕE “TODOS TÊM DIREITO E O ESTADO O DEVER" DEVER DE SAÚDE - COMO AFIANÇAM OS CONSTITUCIONALISTAS, "NA REALIDADE TODOS NÃO TÊM DIREITO, PORQUE A RELAÇÃO JURÍDICA ENTRE O CIDADÃO E O ESTADO DEVEDOR NÃO SE FUNDAMENTA EM VINCULUM JURIS GERADOR DE OBRIGAÇÕES, PELO QUE FALTA AO CIDADÃO O DIREITO SUBJETIVO PÚBLICO, OPONÍVEL AO ESTADO, DE EXIGIR EM JUÍZO, AS PRESTAÇÕES PROMETIDAS A QUE O ESTADO SE OBRIGA POR PROPOSIÇÃO INEFICAZ DOS CONSTITUINTES". NO SISTEMA JURÍDICO PATRIO, A NENHUM ORGÃO OU AUTORIDADE É PERMITIDO REALIZAR DESPESAS SEM A DEVIDA PREVISÃO ORÇAMENTÁRIA, SOB PENA DE INCORRER NO DESVIO DE 
Naquele julgado, o relator, Ministro Demócrito Reinaldo, apontou o caráter tipicamente programático das normas que garantem o direito à saúde, cuja eficácia dependeria de legislação complementar, além da impossibilidade de realização de despesa sem a correspondente previsão orçamentária.

Danielli (2017, p. 60), Desembargador do Tribunal de Justiça de Santa Catarina, elucida que, a partir da década de 90, o Poder Judiciário foi inundado por ações, individuais e coletivas, buscando o fornecimento de medicações para o tratamento da síndrome da imunodeficiência adquirida (SIDA ou AIDS), forçando uma reflexão acerca da exigibilidade do direito à saúde e sua extensão.

De acordo com o ilustre magistrado, "[...] a politização dos reclamos sociais referentes ao tratamento da AIDS foi responsável pela concretização do direito à recuperação da saúde dos pacientes soropositivos, assegurando-lhes o máximo possível prometido constitucionalmente" (DANIELLI, 2017,p. 61).

A partir do ano 2000, o posicionamento dos tribunais superiores se alterou substancialmente. Nesta etapa, as decisões passaram a reconhecer a fundamentalidade do direito à saúde, com a superação de várias teses da Fazenda Pública - como a inaplicabilidade direta do artigo 196 da Constituição Federal de 1988 e a suposta impossibilidade de interferência do Poder Judiciário no orçamento público, de iniciativa exclusiva do Poder Executivo -, porém, sem qualquer ponderação sobre as circunstâncias fáticas e jurídicas, ou mesmo sobre o interesse coletivo.

Com isso, o direito à saúde perdeu o viés meramente programático passou a ser compreendido como um direito subjetivo a uma prestação positiva do Estado, para dar abrigo a toda sorte de pretensões individuais formuladas pelos usuários do 
Sistema Único de Saúde - SUS contra o Poder Público.

No STJ, a mudança pode ser observada com o julgamento do Recurso em Mandado de Segurança n. 11183/PR28, de 22/08/2000:

CONSTITUCIONAL. RECURSO ORDINÁRIO. MANDADO DE SEGURANÇA OBJETIVANDO O FORNECIMENTO DE MEDICAMENTO (RILUZOL/RILUTEK) POR ENTE PÚBLICO À PESSOA PORTADORA DE DOENÇA GRAVE: ESCLEROSE LATERAL AMIOTRÓFICA - ELA. PROTEÇÃO DE DIREITOS FUNDAMENTAIS. DIREITO À VIDA (ART. $5^{\circ}$, CAPUT, CF/88) E DIREITO À SAÚDE (ARTS. $6^{\circ} \mathrm{E} 196, \mathrm{CF} / 88$ ). ILEGALIDADE DA AUTORIDADE COATORA NA EXIGÊNCIA DE CUMPRIMENTO DE FORMALIDADE BUROCRÁTICA. 1 - A existência, a validade, a eficácia e a efetividade da Democracia está na prática dos atos administrativos do Estado voltados para o homem. A eventual ausência de cumprimento de uma formalidade burocrática exigida não pode ser óbice suficiente para impedir a concessão da medida porque não retira, de forma alguma, a gravidade e a urgência da situação da recorrente: a busca para garantia o maior de todos os bens, que é a própria vida. 2 - É dever do Estado assegurar a todos os cidadãos, indistintamente, o direito à saúde, que é fundamental e está consagrado na Constituição da República nos artigos $6^{\circ}$ e 196. 3 - Diante da negativa/ omissão do Estado em prestar atendimento à população carente, que não possui meios para a compra de medicamentos necessários a sua sobrevivência, a jurisprudência vem se fortalecendo no sentido de emitir preceitos pelos quais os necessitados podem alcançar o benefício almejado (STF, AG n ${ }^{\circ}$ 238.328/RS, Rel. Min. Marco Aurélio, DJ 11/05/99; STJ, REsp no 249.026/PR, Rel. Min. José Delgado, DJ 26/06/2000). 4 - Despicienda de quaisquer comentários a discussão a respeito de ser ou não a regra dos arts. $6^{\circ}$ e 196 , da $\mathrm{CF} / 88$, normas programáticas ou de eficácia imediata. Nenhuma regra hermenêutica pode sobrepor-se ao princípio maior estabelecido, em 1988, na Constituição Brasileira, de que 'a saúde é direito de to- 
dos e dever do Estado (art. 196). 5 - Tendo em vista as particularidades do caso concreto, faz-se imprescindível interpretar a lei de forma mais humana, teleológica, em que princípios de ordem ético-jurídica conduzam ao único desfecho justo: decidir pela preservação da vida. 6 - Não se pode apegar, de forma rígida, à letra fria da lei, e sim, considerá-la com temperamentos, tendo-se em vista a intenção do legislador, mormente perante preceitos maiores insculpidos na Carta Magna garantidores do direito à saúde, à vida e à dignidade humana, devendo-se ressaltar o atendimento das necessidades básicas dos cidadãos. 7 Recurso ordinário provido para o fim de compelir o ente público (Estado do Paraná) a fornecer o medicamento Riluzol (Rilutek) indicado para o tratamento da enfermidade da recorrente (BRASIL, 2000, p. 121).

No STF, o julgamento do Agravo Regimental no Recurso Extraordinário n. 271286/RS, de 12/09/2000, espelhou esse novo posicionamento da Corte:

PACIENTE COM HIV/AIDS - PESSOA DESTITUÍDA DE RECURSOS FINANCEIROS - DIREITO À VIDA E À SAÚDE - FORNECIMENTO GRATUITO DE MEDICAMENTOS - DEVER CONSTITUCIONAL DO PODER PÚBLICO (CF, ARTS. 5 , CAPUT, E 196) - PRECEDENTES (STF) - RECURSO DE AGRAVO IMPROVIDO. O DIREITO À SAÚDE REPRESENTA CONSEQÜÊNCIA CONSTITUCIONAL INDISSOCIÁVEL DO DIREITO À VIDA. - O direito público subjetivo à saúde representa prerrogativa jurídica indisponível assegurada à generalidade das pessoas pela própria Constituição da República (art. 196). Traduz bem jurídico constitucionalmente tutelado, por cuja integridade deve velar, de maneira responsável, o Poder Público, a quem incumbe formular - e implementar - políticas sociais e econômicas idôneas que visem a garantir, aos cidadãos, inclusive àqueles portadores do vírus HIV, o acesso universal e igualitário à assistência farmacêutica e médico-hospitalar.

- O direito à saúde - além de qualificar-se como direito fundamental que assiste a todas as pessoas - representa consequência constitucional indissociável do direito à 
vida. O Poder Público, qualquer que seja a esfera institucional de sua atuação no plano da organização federativa brasileira, não pode mostrar-se indiferente ao problema da saúde da população, sob pena de incidir, ainda que por censurável omissão, em grave comportamento inconstitucional. A INTERPRETAÇÃO DA NORMA PROGRAMÁTICA NÃO PODE TRANSFORMÁ- LA EM PROMESSA CONSTITUCIONAL INCONSEQUENTE. - O caráter programático da regra inscrita no art. 196 da Carta Política - que tem por destinatários todos os entes políticos que compõem, no plano institucional, a organização federativa do Estado brasileiro - não pode converter-se em promessa constitucional inconsequente, sob pena de o Poder Público, fraudando justas expectativas nele depositadas pela coletividade, substituir, de maneira ilegítima, o cumprimento de seu impostergável dever, por um gesto irresponsável de infidelidade governamental ao que determina a própria Lei Fundamental do Estado. DISTRIBUIÇÃO GRATUITA DE MEDICAMENTOS A PESSOAS CARENTES. - O reconhecimento judicial da validade jurídica de programas de distribuição gratuita de medicamentos a pessoas carentes, inclusive àquelas portadoras do vírus HIV/AIDS, dá efetividade a preceitos fundamentais da Constituição da República (arts. 5º caput, e 196) e representa, na concreção do seu alcance, um gesto reverente e solidário de apreço à vida e à saúde das pessoas, especialmente daquelas que nada têm e nada possuem, a não ser a consciência de sua própria humanidade e de sua essencial dignidade. Precedentes do STF (BRASIL, 2000b, p. 101).

Essa nova conformação, sem dúvida, foi combustível para que, cada vez mais, o Poder Judiciário fosse acionado para tutelar pretensões não atendidas administrativamente pelo Estado em matéria de saúde.

Assim, em meados da década de 2000, com a Justiça já abarrotada de ações em que se discutia o direito à saúde, os tribunais superiores passaram a adotar um entendimento mais restritivo quanto a essas demandas. Superou-se a compreen- 
são do direito à saúde como princípio absoluto e, com isso, inaugurou-se uma fase em que a solução jurídica impõe a análise das peculiaridades do caso concreto, com considerações técnicas sobre a eficácia dos tratamentos médicos e sobre a própria estrutura do SUS. São exemplos desse momento jurisprudencial: no STJ, o Mandado de Segurança n. 8895/ DF, julgado em 22/10/2003.

ADMINISTRATIVO - SERVIÇO DE SAÚDE - TRATAMENTO NO EXTERIOR - RETINOSE PIGMENTAR. 1. Parecer técnico do Conselho Brasileiro de Oftalmologia desaconselha o tratamento da 'retinoseigmentar' no Centro Internacional de Retinoses Pigmentária em Cuba, o que levou o Ministro da Saúde a baixar a Portaria 763, proibindo o financiamento do tratamento no exterior pelo SUS. 2. Legalidade da proibição, pautada em critérios técnicos e científicos. 3. A Medicina social não pode desperdiçar recursos com tratamentos alternativos, sem constatação quanto ao sucesso nos resultados. 4. Mandado de segurança denegado. (BRASIL, 2003, p. 151).

E, no STF, o Agravo Regimental na Tutela Antecipada n. 175, julgado 17/03/2010.

Suspensão de Segurança. Agravo Regimental. Saúde pública. Direitos fundamentais sociais. Art. 196 da Constituição. Audiência Pública. Sistema Único de Saúde - SUS. Políticas públicas. Judicialização do direito à saúde. Separação de poderes. Parâmetros para solução judicial dos casos concretos que envolvem direito à saúde. Responsabilidade solidária dos entes da Federação em matéria de saúde. Fornecimento de medicamento: Zavesca (miglustat). Fármaco registrado na ANVISA. Não comprovação de grave lesão à ordem, à economia, à saúde e à segurança pública. Possibilidade de ocorrência de dano inverso. Agravo regimental a que se nega provimento. (BRASIL, 2010).

Também em razão do aumento do número de processos e da complexidade dos casos que chegavam ao Poder Judiciário, os ministros do STF observaram a necessidade de estabe- 
lecer balizas e fixar critérios para o julgamento da temática. Assim, no ano de 2009, a Corte Constitucional convocou audiência pública $\left(\mathrm{n}^{\circ} 4\right)$ para subsidiar a análise da judicialização da saúde no Brasil.

Na referida audiência pública, foram discutidos, dentre outros, os seguintes pontos: a) responsabilidade dos entes da federação em matéria de direito saúde; b) obrigação do Estado de fornecer prestação de saúde prescrita por médico não pertencente ao quadro do SUS ou sem que o pedido tenha sido feito previamente à Administração Pública; c) obrigação do Estado de custear prestações de saúde não abrangidas pelas políticas públicas existentes; d) obrigação do Estado de disponibilizar medicamentos ou tratamentos experimentais não registrados na ANVISA ou não aconselhados pelos Protocolos Clínicos do SUS; e) obrigação do Estado de fornecer medicamento não licitado e não previsto nas listas do SUS; e f) fraudes ao Sistema Único de Saúde. (VALE; CAMARGO, 2011, p. 17).

Paralelamente, teve início a atuação do Conselho Nacional de Justiça - CNJ, que criou um Grupo de Trabalho para estudo e proposta de medidas concretas e normativas para as demandas judiciais envolvendo a assistência à saúde (CNJ, Portaria 650, de 20 de novembro de 2009); aprovou a Recomendação n. 31 , de 30 de março de 2010 - que recomenda aos Tribunais a adoção de medidas visando a melhor subsidiar os magistrados e demais operadores do direito, para assegurar maior eficiência na solução das demandas judiciais envolvendo a assistência à saúde -; bem como publicou a Resolução 107, de 6 de abril de 2010 - que institui o Fórum Nacional do Judiciário para monitoramento e resolução das demandas de assistência à saúde.

O Fórum da Saúde é composto pelo Comitê Executivo Nacional, com sede no CNJ, e por Comitês Estaduais (Distrital, no Distrito Federal), cuja criação e manutenção compete aos Tribunais de Justiça e Regionais Federais, e a coor- 
denação aos magistrados, na forma da Resolução $\mathrm{N}^{\mathrm{o}} 238$ de 06/09/2016, do CNJ.

O objetivo do Fórum da Saúde do CNJ é, em última análise, a redução da judicialização, sem, contudo, limitar o exercício da cidadania. Por meio dele, diversas iniciativas vêm sendo adotadas para prevenir a discussão judicial ou, quando inevitável, dar apoio aos envolvidos, a fim de que a resolução da contenda ocorra da forma menos gravosa.

Uma dessas iniciativas é o fomento à criação de Núcleos ou Câmaras de Apoio Técnico pelos Tribunais, órgãos compostos por profissionais da área médica, farmacêutica, assistência social e das Secretarias Municipais de Saúde, cuja finalidade é dar suporte aos magistrados para o exame de processos que envolvem temas da saúde, observando-se na sua criação o disposto no parágrafo segundo do art. 156 do Código de Processo Civil Brasileiro.

Desta forma, com o ajuizamento da demanda, o juiz pode encaminhar cópia da petição inicial e dos documentos ao Núcleo de Apoio Técnico- NAT ou à Câmara Técnica, para que o órgão informe, por exemplo, se o medicamento tem registro na ANVISA; se é eficaz para o tratamento da doença; se existe medicamento similar fornecido pelo SUS; e se há eficiência, eficácia e o custo-efetividade do tratamento proposto. Além disso, o órgão pode auxiliar no cumprimento das decisões judiciais, na facilitação da defesa dos entes públicos, na simplificação do atendimento pela Defensoria Pública, na facilitação da celebração de acordos, bem como contribuir com a produção de provas, participando de audiências e emitindo pareceres. (SCHULZE; NETO, 2015, p. 83-84).

No Estado de Santa Catarina, o caminho trilhado pelo Poder Público vai ao encontro das diretrizes estabelecidas pelo CNJ.

De acordo com o procurador do Estado Daniel Cardoso, 
consultor jurídico da Secretaria Estadual da Saúde:

Em 2016, foram gastos cerca de R\$ 155 milhões para atender a decisões judiciais que obrigam o Estado de SC a fornecer remédios e tratamentos médicos não padronizados pelo SUS. 'Em muitos casos existem medicamentos similares, com a mesma efetividade, que são distribuídos gratuitamente. Porém, alguns juízes não têm conhecimento disso e acolhem pedidos de remédios que não têm a sua eficiência comprovada ou que são muito mais caros, onerando o já apertado orçamento da Saúde.'(SANTA CATARINA, 2017, p.5).

$\mathrm{O}$ aumento vertiginoso dos gastos públicos e do número de processos judiciais com demandas relacionadas à saúde levaram o Poder Público estadual a adotar diversas medidas que para a solução desses conflitos.

No âmbito do Poder Judiciário, o egrégio Tribunal de Justiça do Estado de Santa Catarina analisou a matéria em Incidente de Resolução de Demandas Repetitivas (Tema 1), firmando as seguintes teses:

[... 1.1 Para a concessão judicial de remédio ou tratamento constante do rol do SUS, devem ser conjugados os seguintes requisitos: (1) a necessidade do fármaco perseguido e adequação à enfermidade apresentada, atestada por médico; (2) a demonstração, por qualquer modo, de impossibilidade ou empecilho à obtenção pela via administrativa (Tema 350 do STF).

1.2 Para a concessão judicial de fármaco ou procedimento não padronizado pelo SUS, são requisitos imprescindíveis: (1) a efetiva demonstração de hipossuficiência financeira; (2) ausência de política pública destinada à enfermidade em questão ou sua ineficiência, somada à prova da necessidade do fármaco buscado por todos os meios, inclusive mediante perícia médica; (3) nas demandas voltadas aos cuidados elementares à saúde e à vida, ligando-se à noção de dignidade humana (mínimo existencial), dispensam-se outras digressões; (4) nas demandas cla- 
ramente voltadas à concretização do máximo desejável, faz-se necessária a aplicação da metodologia da ponderação dos valores jusfundamentais, sopesando-se eventual colisão de princípios antagônicos (proporcionalidade em sentido estrito) e circunstâncias fáticas do caso concreto (necessidade e adequação), além da cláusula da reserva do possível. (SANTA CATARINA, 2016).

Portanto, a partir desse julgamento, na Justiça Estadual Catarinense, as decisões nas demandas que veiculam a pretensão de fornecimento de medicamentos ou a realização de procedimentos voltados à saúde, obrigatoriamente, devem observar as teses acima mencionadas, conforme estabelece o Código de Processo Civil Brasileiro nos seus artigos art. 927, III, e 985, II.

Mais recentemente, o Superior Tribunal de Justiça definiu os requisitos para o fornecimento de medicamentos que estão fora da lista do SUS. A Primeira Seção do STJ concluiu o julgamento do Resp. 1657156, julgado sob a sistemática dos Recursos Repetitivos, firmando a tese segundo a qual constitui obrigação do Poder Público o fornecimento de medicamentos que não estão incorporados em atos normativos do SUS, desde que presentes os seguintes requisitos:

1 - Comprovação, por meio de laudo médico fundamentado e circunstanciado, expedido pelo médico que assiste o paciente, da imprescindibilidade ou necessidade do medicamento, assim como da ineficácia, para o tratamento da moléstia, dos fármacos fornecidos pelo SUS;

2 - Incapacidade financeira do paciente de arcar com o custo do medicamento prescrito; e;

3 - Existência de registro do medicamento na Agência Nacional de Vigilância Sanitária (Anvisa). (BRASIL, 2018, p. 1).

Vale ressaltar que, segundo veiculado no sítio eletrônico do Tribunal da Cidadania, o recurso julgado é o primeiro repetitivo no qual o STJ aplicou a modulação de efeitos pre- 
vista no art. 927, $\S 3^{\circ}$, do Código de Processo Civil de 2015, para considerar que os requisitos acima listados somente serão exigidos nos processos distribuídos a partir da conclusão daquele julgamento.

Desta forma, a tese fixada não deverá ser obrigatoriamente observada nos processos que ficaram sobrestados desde a afetação do tema, cadastrado sob o número 106.

Por fim, na referida decisão, também se determinou que, após o trânsito em julgado de cada processo, o Ministério da Saúde e a Comissão Nacional de Tecnologias do SUS - CONITEC, deverão ser cientificados, a fim de promoverem estudos sobre a viabilidade de incorporação do fármaco na listagem do SUS.

Já o Poder Executivo vem focando suas ações na solução extrajudicial de conflitos, ao apoio técnico aos juízes, bem como ao estabelecimento de vetores para a concessão de medicamentos ou tratamentos médicos.

No ano de 2012, foi instalado o Comitê Estadual de Monitoramento e Resolução das Demandas de Assistência da Saúde de Santa Catarina-COMESC, integrado por representantes do Poder Judiciário, do Ministério Público, da Ordem dos Advogados do Brasil, do Poder Executivo, da Defensoria Pública, da sociedade civil e de comunidades interessadas.

O COMESC realiza reuniões mensais e promove debates de consensos, dando ensejo a enunciados e recomendações que tratam sobre temas comuns nas ações judiciais voltadas à área da saúde. Tais enunciados e recomendações buscam uniformizar procedimentos a serem adotados pelos profissionais de saúde e do direito, bem como priorizar a assistência à saúde, a organização do SUS e o desenvolvimento, de modo isonômico, das políticas públicas voltadas aos seus usuários, sendo encaminhados aos magistrados pela Corregedoria-Geral da Justiça. (SANTA CATARINA, 2018). 
Outra importante iniciativa foi a criação de Núcleos de Apoio Técnico- NAT.

Em 2015, o Tribunal de Justiça de Santa Catarina e a Secretaria Estadual de Saúde, atendendo ao disposto na Resolução $\mathrm{n}^{\mathrm{o}} 238$ do CNJ, firmaram convênio para a criação do Núcleo de Apoio Técnico - NAT, com o objetivo de fornecer, via troca de informações institucionais, subsídios técnicos aos magistrados nas ações oriundas das comarcas da Capital e da Grande Florianópolis que busquem compelir o Estado de Santa Catarina ao fornecimento de medicamentos e de componentes nutricionais, com a promessa de que, bem-sucedido, o atendimento seria estendido a outras comarcas catarinenses de forma gradativa. (SANTA CATARINA, 2018).

Instituído pela Portaria $n^{\circ}$ 991/2015/SES e regulamentado pela Portaria $n^{\circ}$ 1034/2016/SES, o Núcleo de Apoio Técnico - NAT, tem por finalidade assessorar o Poder Judiciário, subsidiando os magistrados com informações técnicas e esclarecedoras sobre o atendimento no SUS, mediante análise crítica dos fatos alegados na demanda judicial, na forma de parecer científico; bem como otimizar o atendimento do usuário, mediante a indicação do tratamento preconizado no SUS, quando existir, e, na sua ausência, da alternativa terapêutica existente. (Portaria $\mathrm{n}^{\mathrm{o}}$ 1034/2016/SES, art. $3^{\circ}$ ).

No município de Joinville, umas das estratégias do Poder Executivo local também é a redução do comprometimento financeiro com os processos judiciais ligados à saúde.

Segundo o Plano Municipal de Saúde 2014-2017, no ano de 2013, a proporção dos gastos com medicamentos devido a demandas judiciais era de 50\% e a meta para 2017 estima a redução para 33\%. (JOINVILLE, 2017).

Nesse contexto, no ano de 2016, foi editado o Decreto $\mathrm{n}^{\mathrm{o}}$ 26.981 , de 15 de junho de 2016, posteriormente alterado pelo 
Decreto ${ }^{\circ} 30.043$, de 14 de novembro de 2017, que instituiu o Núcleo de Apoio Técnico - NAT no município de Joinville, com o objetivo, entre outros, de regulamentar os procedimentos voltados à prevenção e resolução administrativa de litígios na saúde.

O NAT do Município de Joinville tem sede na Secretaria Municipal de Saúde e atua fundamentalmente de dois modos.

A primeira linha de ação do órgão é dar apoio técnico Poder Judiciário, ao Ministério Público e à Defensoria Pública e aos advogados em representação aos usuários efetivos do SUS das regiões Norte e Nordeste do Estado de Santa Catarina, com a elaboração de pareceres técnicos a respeito das matérias da sua competência, a exemplo do que já é feito pelo NAT estadual.

A medida é de grande relevância. Isso porque existe uma lista de medicamentos padronizados, a RENAME - Relação Nacional de Medicamentos Essenciais - , que define os medicamentos que devem atender às necessidades de saúde prioritárias da população brasileira no Sistema Único de Saúde (SUS), a qual muitas vezes não é observada pelos próprios médicos, seja porque eles desconhecem o seu conteúdo ou porque têm preferência por determinado produto/procedimento.

Assim, o parecer do NAT pode auxiliar os magistrados a decidir de modo mais técnico sobre a concessão judicial determinado medicamento/procedimento/material, esclarecendo se há registro na ANVISA; se a prescrição é eficaz para o tratamento; se existe medicamento/procedimento/material similar fornecido pelo SUS; e se há eficiência, eficácia e o custo-efetividade do que foi prescrito pelo médico.

$\mathrm{Na} 1^{\text {a }}$ Vara da Fazenda da Comarca de Joinville, o apoio do NAT já tem sido utilizado. Naquela unidade, há casos em que a manifestação do NAT substitui a prova pericial tradicional, o que torna o processo mais célere e menos oneroso. 
A outra linha de ação do NAT é preventiva, denominada "Sistema de Prevenção e Resolução Administrativa de Litígios na Saúde".

Nesse fluxo, o Ministério Público do Estado de Santa Catarina, a Defensoria Pública do Estado de Santa Catarina, o Ministério Público Federal, a Defensoria Pública da União, os Núcleos de Prática Jurídica das Faculdades de Direito, os advogados de usuários efetivos do SUS e as diversas unidades ou serviços componentes do SUS em Joinville poderão formular requerimentos administrativos para o fornecimento de medicamentos, materiais e procedimentos de saúde.

Todo o procedimento é realizado eletronicamente. Em breve síntese, o requerimento formal é encaminhado ao e-mail do órgão (ou via Sistema Telessaúde - em fase de implantação,TELESSAÚDE, 2018), acompanhado da prescrição médica, de relatório médico padronizado pelo NAT e de documentos pessoais do usuário (apenas residentes no município de Joinville podem ser atendidos pelo serviço). Em seguida, o pedido é avaliado pela equipe de profissionais de saúde do NAT (farmacêuticos e médicos), que elaboram seus pareceres. Por fim, é proferida a decisão administrativa, que pode ser pelo deferimento, pelo deferimento parcial, pelo indeferimento, pelo arquivamento ou então pelo encaminhamento requerente ao ente público responsável pelo fornecimento do medicamento/procedimento/material postulado, caso não seja o Município de Joinville.

Há casos, porém, em que se constata a existência de alternativas terapêuticas, diagnósticas ou procedimentais, disponibilizadas pelo SUS, com relação custo-efetividade igual ou superior à apresentada pelo item solicitado. Nesses casos, o NAT pode designar sessão de conciliação para viabilizar a resolução consensual do pedido, com a presença obrigatória de um representante do órgão, um representante da área técnica do item solicitado, o usuário solicitante, um representante do 
órgão/unidade de origem e o profissional prescritor do item pleiteado. Não exitosa a conciliação, o procedimento é encaminhado para decisão administrativa.

O Relatório Anual de Monitoramento da Judicialização - 2017 da Secretaria Municipal de Saúde faz uma análise histórica dos indicadores referentes à judicialização da saúde pública e à resolução administrativa de litígios no Município de Joinville e aponta que o NAT já está apresentando resultados muito satisfatórios.

De acordo com o referido documento, o NAT recebeu 272 requerimentos administrativos em 2017, o que representa um crescimento de 697\% em relação ao ano anterior (em 2016 foram apenas 39).

Ainda, informa que das 228 solicitações que foram efetivamente analisadas pelo NAT em 2017, 129 foram deferidas, 5 foram parcialmente deferidas, 37 foram indeferidas, 53 foram arquivadas e 4 foram encaminhadas para outros entes federativos.

E mais, demonstra que no ano de 2017, o número de novas ações judiciais por meio das quais se pretendia o fornecimento de medicamentos, insumos, procedimentos e outros serviços de saúde (227 novas ações) foi aproximadamente 23\% menor que o registrado em 2016 (294 novas ações) e que nos anos de 2015, 2016 e 2017, a redução acumulada no número de novas ações correspondeu a 31,63\% (-28,47\% na Justiça Estadual e $-17,33 \%$ na Justiça Federal, (JOINVILLE, 2017).

Por fim, aponta que no ano de 2017, o Município de Joinville empenhou um total de $\mathrm{R} \$$ 6.053.061,97 (seis milhões, cinquenta e três mil, sessenta e um reais e noventa e sete centavos), $41,46 \%$ a menos que o montante empenhado no ano de 2016, que foi de R $\$ 10.403 .695,04$ (dez milhões, quatrocentos e três mil, seiscentos e noventa e cinco reais e quatro centavos, JOINVILLE, 2017). 
Diante da realidade estampada, outra não pode ser a conclusão, senão a de que a criação do NAT no Município de Joinville é uma ação administrativa dotada de efetividade.

Para entender melhor o conceito de efetividade, valho-me das lições de Motta (1990, p. 230 apud GOMES, 2009, p. 19):

Eficiência refere-se ao cumprimento de normas e à redução de custos. Sua utilidade é verificar se um programa público foi executado de maneira mais competente e segundo a melhor relação custo-resultado. Eficácia refere-se ao alcance de resultados e à qualidade dos produtos e serviços e sua utilidade é verificar se os resultados previstos foram alcançados em termos de quantidade e qualidade. A efetividade, por sua vez, refere-se ao efeito da decisão pública e sua utilidade é verificar se o programa responde adequadamente às demandas, aos apoios e às necessidades da comunidade. Em outras palavras, avaliar eficiência é saber como aconteceu; a eficácia, o que aconteceu; a efetividade, que diferença faz.

Assim, eficiência é a capacidade de utilizar produtivamente os recursos, segundo a melhor relação custo-benefício; eficácia é a capacidade de realizar objetivos, a relação entre as metas pretendidas e as metas alcançadas; e a efetividade é capacidade de produzir um resultado para transformar a situação existente, respondendo adequadamente às necessidades da comunidade.

Por certo, "O desejável é que tais qualificações caminhem simultaneamente, mas é possível admitir que haja condutas administrativas produzidas em eficiência, embora não tenham eficácia ou efetividade." (CAMARGO; GUIMARÃES, 2013, p.139).

Com efeito, o apoio técnico do NAT dá aos Magistrados, Promotores de Justiça e Defensores Públicos informações sobre medicamentos/procedimentos/materiais padronizados, aponta quais são os tratamentos mais adequados para cada caso e, eventualmente, fornece instruções sobre a relação custo-e- 
fetividade da prescrição médica pleiteada, garantindo que as decisões judiciais sejam cada vez mais técnicas e sofisticadas.

Os números do Relatório Anual de Monitoramento da Judicialização - 2017 mostram que, entre 2016 (início das atividades do Sistema de Prevenção e Resolução Administrativa de Litígios) e 2017, houve a redução de, aproximadamente, $23 \%$ no número de novas ações judiciais na Comarca de Joinville e de $41,46 \%$ no montante empenhado pelo ente público municipal com as demandas por medicamentos/procedimentos/materiais de saúde.

Além disso, com essa nova conformação de resolução extrajudicial de demandas, o atendimento ao usuário do SUS também se tornou mais célere. As informações sobre o fornecimento de medicamentos/procedimentos/materiais de saúde foram centralizadas em um único órgão, o mesmo que tem como atribuição processar e analisar os requerimentos administrativos formulados pelos usuários do SUS. Com isso, ao ser atendido na sua unidade de saúde, o usuário é inserido no sistema de informação da Prefeitura de Joinville e os seus requerimentos relacionados a medicamentos/procedimentos/materiais de saúde são, de modo padronizado e eletrônico, enviados ao NAT, que fará a avaliação de cada caso, individualmente, e informará a decisão à unidade de saúde de origem, sem que haja a necessidade de deslocamentos do cidadão.

Portanto, é possível concluir que a instauração do NAT no Município de Joinville é conduta administrativa dotada de efetividade, porquanto reduziu consideravelmente o número de processos judiciais que buscam medicamentos/procedimentos/ materiais relativos à saúde em face do Município de Joinville, contribuiu para a diminuição do empenho de valores do orçamento público com tais demandas e facilitou o acesso do usuário às informações e serviços do SUS. 


\section{CONCLUSÃO}

Sem a pretensão de esgotar o tema, buscou-se com este artigo demonstrar que a resolução de conflitos que envolvem o direito à saúde merece aperfeiçoamento não apenas na seara jurídica, mas, sobretudo, no período pré-processual, com soluções extrajudiciais.

Para tanto, foi realizado um breve resgate histórico da judicialização da saúde no Brasil, com a análise da evolução da jurisprudência sobre o tema e das medidas adotadas pelo Poder Público para conter o crescimento exponencial do número de processos judiciais e dos gastos públicos correspondentes.

Neste ponto, observou-se que, num primeiro momento, os Tribunais Superiores vedavam qualquer forma de interferência do Poder Judiciário nas políticas públicas de saúde. Passo seguinte, a orientação se inverteu e o direito à saúde passou a ser compreendido como um direito subjetivo a uma prestação positiva do Estado, para dar abrigo a toda sorte de pretensão individual formulada pelos usuários do Sistema Único de Saúde - SUS contra o Poder Público. Finalmente, com a Justiça já abarrotada de ações em que se discutia o direito à saúde, os tribunais superiores passaram a adotar um entendimento mais restritivo quanto a essas demandas. Inaugurou-se uma fase em que a solução jurídica impõe a análise das peculiaridades do caso concreto, com considerações técnicas sobre a eficácia dos tratamentos médicos e sobre a própria estrutura do SUS.

Em continuidade, foram apontadas as medidas adotadas pelo Poder Público para controlar o número de processos judiciais e as contas públicas, ao mesmo tempo em que se confere eficácia ao direito à saúde estampado na Constituição Federal.

Como exemplo, foram citadas a Audiência Pública promovida pelo STF em 2009, a atuação do CNJ, com resoluções e recomendações aos Tribunais do país e a experiência no Esta- 
do de Santa Catarina com a criação do NAT.

Em arremate, foi analisada a instituição do NAT no Município de Joinville, com a avaliação dos indicadores apresentados pela Secretaria Municipal de Saúde no Relatório Anual de Monitoramento da Judicialização - 2017, onde se demonstrou que a sua atuação tem sido efetiva na redução do número de ações judiciais em que se pleiteiam medicamentos/procedimentos/materiais relativos à saúde na Comarca de Joinville e, consequentemente, na diminuição do comprometimento do orçamento público com essas demandas.

Por todo o exposto, deseja-se que a presente pesquisa seja útil para que todas essas iniciativas sejam replicadas e aperfeiçoadas, com vistas a uma prestação de serviço público de saúde mais célere, eficiente, eficaz e efetiva.

\section{REFERÊNCIAS}

ALEXY, Robert. Teoria dos direitos fundamentais. Tradução Virgílio Afonso da Silva. São Paulo: Malheiros, 2011.

BALESTRA NETO, Otávio. A jurisprudência dos tribunais superiores e o direito à saúde - evolução rumo à racionalidade. Revista de Direito Sanitário, São Paulo, v. 16, n. 1, p. 87-111, jul. 2015. Disponível em: <http://www.revistas.usp.br/rdisan/article/ view/100025>. Acesso em: 21 mar. 2018. doi:http://dx.doi.org/10.11606/issn.23169044.v16ilp87-111.

BARROSO, Luís Roberto. A dignidade da pessoa humana no direito constitucional contemporâneo: a construção de um conceito jurídico à luz da jurisprudência mundial. Tradução Humberto Laport de Mello. 3. reimpr. Belo Horizonte: Fórum, 2014.

BRASIL. Constituição da República Federativa do Brasil (1988). Disponível em: $<$ http://www.planalto.gov.br/ccivil_03/constituicao/constituicaocompilado.htm>. Acesso em: 19 jan. 2018.

. Supremo Tribunal Federal. AgRg no RE 271.286/RS, segunda turma. Min. Celso de Mello. j. 12/09/2000, DJ 24/11/2000b, p. 101.

$\overline{\text { DJe } 29 / 0} \overline{4 / 2010 .}$

STA 175-AgR/CE, pleno, rel. Min. Gilmar Mendes. j. 17/03/2010,

. Superior Tribunal de Justiça. MS 8895/DF, primeira seção, Rel. Min. Eliana Calmon. j. 22/10/2003, DJ 07/06/2004, p. 151.

Recurso Repetitivo. Primeira seção define requisitos para forne-

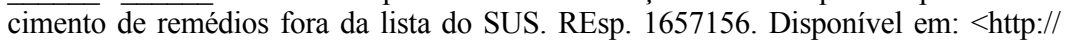


www.stj.jus.br/sites/STJ/default/pt_BR/Comunica\%C3\%A7\%C3\%A3o/noticias/No$\mathrm{t} \% \mathrm{C} 3 \% \mathrm{ADcias} /$ Primeira-Se $\% \mathrm{C} 3 \% \mathrm{~A} 7 \% \mathrm{C} 3 \% \mathrm{~A} 30$-define-requisitos-para-fornecimento-de-rem\%C3\%A9dios-fora-da-lista-do-SUS>. Acesso em: 22 mar. 2018.

RMS 6564/RS, primeira turma, Rel. Min. Demócrito Reinaldo. DJe. $\overline{23 / 05 / 1} \overline{96, \text { DJe }}$ 17/06/1996, p. 21448.

. RMS 11183/PR, primeira turma, Rel. Min. José Delgado. j.

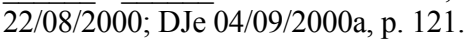

CAMARGO, Franciele de O.; GUIMARÃES, Klícia M.S. O princípio da eficiência na gestão pública. Revista CEPPG - CESUC - Centro de Ensino Superior de Catalão, a. XVI, n. 28, $1^{\circ}$ Semestre/2013. p. 133-145.

CARVALHO FILHO. José dos Santos. Manual de direito administrativo. 31. ed. rev. atual. e ampl. São Paulo: Atlas, 2017.

CNJ. Conselho Nacional de Justiça. Portaria 650, de 20 de novembro de 2009. Disponível em: <http://www.cnj.jus.br/busca-atos-adm?documento=496>. Acesso em: 19 jan. 2018.

Recomendação COMESC no1/2012. Disponível em: <http://www.

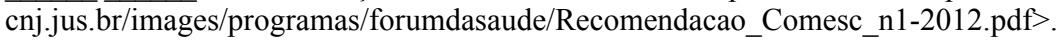
Acesso em: 19 jan. 2018.

Recomendação n. 31, de 30 de março de 2010. Disponível em: <http:// www.cnj.jus.br/atos-normativos?documento=877>. Acesso em: 19 jan. 2018.

Resolução 107, de 6 de abril de 2010. Disponível em: <http://www. cnj.jus.br/atos-normativos?documento=173>. Acesso em: 19 jan. 2018.

Resolução No 238 de 06/09/2016. Disponível em: <http://www.cnj.jus. br/busca-atos-adm?documento=3191>. Acesso em: 19 jan. 2018.

Resolução No 238 de 06/09/2016. Ementa: Dispõe sobre a criação e manutenção, pelos Tribunais de Justiça e Regionais Federais de Comitês Estaduais da Saúde, bem como a especialização de vara em comarcas com mais de uma vara de fazenda Pública. Disponível em: $<$ http://www.cnj.jus.br/busca-atos-adm?documento $=3191>$. Acesso em: 28 mar. 2018.

DANIELLE, Ronei. A judicialização da saúde no Brasil: do viés individualista ao patamar do bem estar coletivo. Belo Horizonte: Fórum, 2017.

GENTIL, Raquel de Matos Lopes et al. (Org.). Direito da saúde em perspectiva: judicialização, gestão e acesso. Vitória: Editora Emescam, 2016.

GOMES, Eduardo G M. Gestão por resultados e eficiência na administração públi$c a$ : uma análise à luz da experiência de Minas Gerais. Tese de doutorado. Disponível: $<$ http://www.planejamento.gov.br/secretarias/upload/Arquivos/seges/EPPGG/producaoAcademica/tese_EduardoGranha.pdf>. Acesso em: 10 mar. 2018.

HOSSEPIAN. Arnaldo. Judicialização da saúde requer informação qualificada para impedir abusos. Disponível em: <https:/www.conjur.com.br/2017-abr-05/hossepianjudicializacao-saude-requer-informacao-qualificada>. Acesso em: 2 fev. 2018.

JOINVILLE (Cidade). Plano municipal de saúde 2017-217. Disponível em: <https:// www.joinville.sc.gov.br/wp-content/uploads/2017/03/Plano-Municipal-de-Sa\%- 
C3\%BAde-do-Munic\%C3\%ADpio-de-Joinville-referente-a-2014-2017.pdf>. Acesso em: 22 fev. 2018.

SANTA CATARINA. Governo do Estado de Santa Catarina. Comitê Estadual de Monitoramento e Resolução das Demandas de Assistência da Saúde de Santa Catarina - COMESC. Disponível em: <http://portalses.saude.sc.gov.br/index.php?option=com content\&view $=$ article\&id=4949\&Itemid=668> . Acesso em: 19 jan. 2018.

. Núcleo deve auxiliar juízes catarinenses em decisões sobre medicamentos. Disponível em: <http:/www.sc.gov.br/index.php/noticias/temas/justica-edefesa-da-cidadania/nucleo-deve-auxiliar-juizes-catarinenses-em-decisoes-sobremedicamentos>. Acesso em: 22 fev. 2018.

Portaria $n^{\circ}$ 1034/2016/SES. Disponível em: <http://www.doe.sea.sc.gov.br/

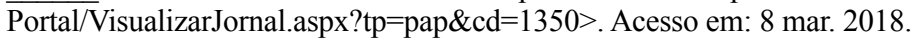

Procuradoria Geral do Estado. Juízes de Ibirama determinam que ações judiciais contra o Estado pedindo medicamentos devam conter informações comprovando necessidade. Disponível em: <http://www.pge.sc.gov.br/index.php/sinopse-dodia/2055-8-6-2017>. Acesso em: 22 fev. 2018.

. Tribunal de Justiça de Santa Catarina. Convênio firmado assegura apoio técnico para magistrados em ações de medicamentos. Disponível em: $<$ https://portal.tjsc. jus.br/web/sala-de-imprensa/-/convenio-firmado-assegura-apoio-tecnico-para-magistrados-em-acoes-de-medicamentos>. Acesso em: 2 fev. 2018.

SCHULZE, Clenio; GEBRAN NET, João Pedro. Direito à saúde análise à luz da judicialização. Porto Alegre: Verbo Jurídico, 2015.

SILVA, José Afonso da. Curso de direito constitucional positivo. 4. ed. rev. e atual. até a Emenda Constitucional n. 95, de 15.12.2016. São Paulo: Malheiros, 2017.

TELESSAÚDE. Disponível em: <https://telemedicina.saude.sc.gov.br>. Acesso em: 22 fev. 2018.

VALLE, Gustavo Henrique Moreira do; CAMARGO, João Marcos Pires. A audiência pública sobre a judicialização da saúde e seus reflexos na jurisprudência do supremo tribunal federal. Revista de Direito Sanitário, São Paulo, v. 11, n. 3, p. 13-31, fev. 2011. Disponível em: <http://www.revistas.usp.br/rdisan/article/view/13220>. Acesso em: 1 mar. 2018. doi:http://dx.doi.org/10.11606/issn.2316-9044.v11i3p13-31.

Recebido em: 10/05/2018

Aprovado em: 23/07/2018 